\title{
Urgences
}

\section{JeanCossette, Le transit des fées, Rimouski, Éditeq, 1983.}

\section{Françoise Daigle}

\section{Numéro 9, 1er trimestre 1984}

URI : https://id.erudit.org/iderudit/025144ar

DOI : https://doi.org/10.7202/025144ar

Aller au sommaire du numéro

Éditeur(s)

Urgences

ISSN

0226-9554 (imprimé)

1927-3924 (numérique)

Découvrir la revue

Citer ce compte rendu

Daigle, F. (1984). Compte rendu de [JeanCossette, Le transit des fées, Rimouski, Éditeq, 1983.] Urgences, (9), 91-93. https://doi.org/10.7202/025144ar

Ce document est protégé par la loi sur le droit d'auteur. L'utilisation des services d'Érudit (y compris la reproduction) est assujettie à sa politique d'utilisation que vous pouvez consulter en ligne.

https://apropos.erudit.org/fr/usagers/politique-dutilisation/
Cet article est diffusé et préservé par Érudit.

Érudit est un consortium interuniversitaire sans but lucratif composé de l'Université de Montréal, l'Université Laval et l'Université du Québec à Montréal. Il a pour mission la promotion et la valorisation de la recherche. https://www.erudit.org/fr/ 


\section{PARUTIONS COMMENTÉES}

LE TRANSIT DES FÉES, de Jean Cossette, Editeq, 1983.

"Il faut toujours voir au-delà, prendre tout pour une fenêtre. L'important, dans tout cela, n'est pas tellement la fenêtre elle-même que le panorama sur lequel elle donne*"...

Très sage conseil de lecture que nous donnait là Roland Giguère. Et pourtant, il aut bien ajouter qu'il y a fenêtre et fenêtre. Des rebutantes et des mal vernies, des opaques et des claires, des mal équarries et des soignées... Le recueil de Jean Cossette, quant à lui, s'ouvre doucement comme une fenêtre bien huilée. Et c'est agréable de se sentir apprivoisé, séduit en douce! Car on se glisse aisément dans I'univers du Transit des fées.

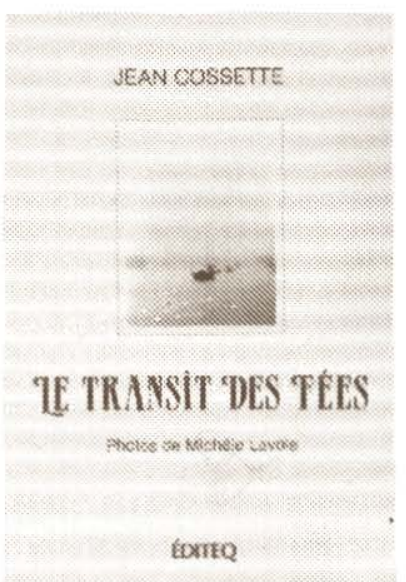

C'est peut-être parce qu'on ne nous bouscule jamais: rien ici de brusquement tranché. Une poésie toute en nuances, mais sans aucune certitude, puisque toute réalité présente un envers: à l'envers de l'amour, il y a l'attente et

* Roland Giguère, Foret vierge folle. Paris, éd. de l'Hexagone, 1978. page 19. 
I'absence. À l'envers de l'enfance, il y a la mort inévitable. De l'autre côté de l'émerveillement, la désillusion; du rêve, le mirage. Partout ce goût très ardent du départ, et cependant, cet entêtement à rester. Ce thème du voyage, qui est d'ailleurs abordé dès les premières pages, est peut-être celui qui illustre le mieux ce déchirement entre le désir et I'impossibilité de le réaliser. Tout le livre nous souffle cet appel de l'ailleurs, ce désir de partir. Et pourtant, I'on ne part jamais. Le poète nous parle en effet continuellement des "pays que nous ne verrons jamais" (p. 19) des "voyages (...) que tu n'as jamais faits" (p. 28), de cette "pauvre Anne qui n'est jamais partie" (p. 47), et ainsi de suite...

Et pourquoi donc ne pas partir, direz-vous. C'est que les obstacles paraissent si insurmontables que le projet à peine ébauché est déjà avorté. Tout effort semble inutile. Dans ce contexte, tous se révèle rapidement vain et illusoire. À quoi bon tenter quoi que ce soit, puisque tout meurt déjà, puisque tout est éphémère, des souvenirs (p. 22) aux bonheurs (p. 27) en passant par l'angoisse et I'oubli (pp. 25 et 26). La certitude lancinante de tourner en rond, de ne jamais aboutir. L'image de la mer, avec ses ressacs et ses marées, domine d'ailleurs le recueil, et cristallise bien ce thème du retour sans fin. Comme la vague déferle et revient sur elle-même continuellement, le poète se jette tour à tour dans l'espoir puis la désillusion...

Dans ce monde désabusé, les évasions ne sont pas faciles. II faut chercher un "espace second", où sera enfin tenue "la promesse d'un temps d'arrêt" (p. 28). Cet espace second réside peut-être dans I'amour, et surtout dans I'extase de l'amour, cet étonnement sans fin. Ou alors il se trouve dans le dire, la parole. De toute façon, la fuite est toujours brève, et ne permet qu'un instant seulement d'oublier "I'horizon ébréché", ce futur sans promesses.

Voilà donc un rapide portrait de l'oeuvre qui vous convaincra, je l'espère, de la densité et de la consistance de la thématique chez Jean Cossette. 
Bien sûr, il s'agit d'un premier recueil, et donc, d'une écriture qu'il reste à mûrir. On pourrait surtout reprocher au poème le manque d'unité, de cohésion: il est parfois difficile d'en dégager l'idée ou l'image dominante. C'est que dans son enthousiasme à tout dire, le poète en dit trop. II faudrait sans doute raccourcir le poème et soigner les chutes. Dans ce sens, les exergues courtes et percutantes sont très réussies. Une autre faiblesse réside dans I'architecture du recueil. Les divisions de chapitres peuvent sembler artificielles, ou du moins, elles ne sont pas commandées par l'évidence.

Mais tout cela se compense par l'authenticité de la recherche poétique, par un imaginaire qui se révèle riche, et par de très belles images.

Prenons également le temps de souligner la qualité de la plupart des photographies contenues dans le recueil. Les photos de Michèle Lavoie sont choisies tr̀es justement. Elles se veulent l'illustration du poème, mais elles ouvrent aussi une dimension supplémentaire: celle de la rêverie déclenchée par l'image. Et cela, c'est aussi de la poésie...

Et puisque le plaisir de manipuler un livre demeure aussi l'un des charmes de la lecture, il faut apprécier à juste titre le "physique" du recueil. En effet, le format, la couleur et la forme des caractères, tout concourt à nous être agréable.

Toutes considérations faites, donc, le recueil de Jean Cossette nous révèle une poésie pleine de promesses.

On attend, évidemment, la suite...

Françoise Daigle 